\title{
CORRELACÃO ENTRE PROPRIEDADES LOCAIS DE NANOPARTÍCULAS PLAMÔNICAS E A ESTATÍSTICA DE OBSERVAÇÃO DE ESPECTROS SERS.
}

\section{Dayane V. N. dos Santos*, Diego P. dos Santos}

\section{Resumo}

Neste trabalho exploramos do ponto de vista teórico, através de simulações eletrodinâmicas clássicas, a correlação entre as características do campo elétrico apresentado na superfície de nanopartículas (NP) metálicas com o perfil da distribuição de intensidades em um experimento SERS (Espalhamento Raman Intensificado por Superfícies) de uma única molécula. Os resultados indicam a possibilidade de obter informações sobre o substrato de NPs a partir do formato dos histogramas de intensidade.

\section{Palavras-chave:}

\section{Espectroscopia Raman, SERS, Plasmon.}

\section{Introdução}

Ao longo dos anos tem-se aumentado o interesse no estudo de nanopartículas metálicas devido a sua grande aplicabilidade. $\mathrm{Na}$ espectroscopia aprimorada, por exemplo, o espelhamento Raman intensificado por superfícies (SERS) utiliza tais nanopartículas para aumentar várias ordens de grandeza o campo elétrico sentido por uma molécula adsorvida. O aumento do campo leva a aumento do sinal observado em um experimento SERS.

A intensificação do sinal atribuído ao mecanismo eletromagnético surge da excitação ressonante de modos de oscilação coletiva dos elétrons da superfície da NP, tais modos de excitação coletiva são chamados de plasmon de superfície e dependem das propriedades do substrato metálico utilizado ${ }^{1}$. Em NPs esféricas, o incremento ocorre principalmente em interstícios entre duas partículas com distâncias da ordem de $1 \mathrm{~nm}$, essas regiões são chamadas de hot spots $(\mathrm{HS})^{2}$ e podem ser esquematizadas como na figura 1:

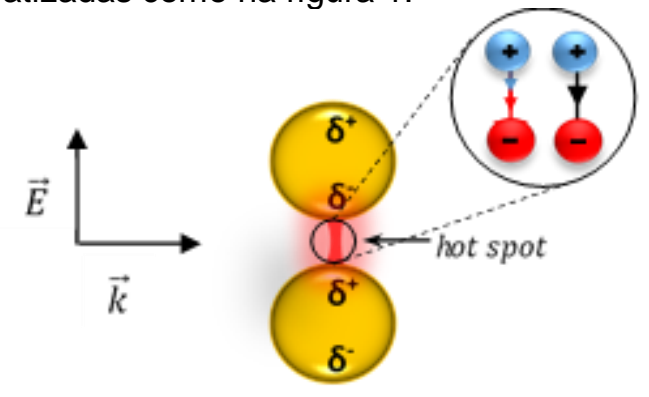

Figura 1. Hot spot de um dímero.

A ideia explorada nesse trabalho é de olhar para o HS além de suas aplicações analíticas e obter informações sobre suas características, que refletem o tipo de substrato presente, através de histogramas experimentais de espectros SERS de uma única molécula. Atualmente essa informação só é acessível por espectroscopia de perda de energia de elétrons (EELS).

\section{Resultados e Discussão}

A análise foi feita considerando o HS presente em três sistemas distintos de nanopartículas de ouro (AuNP): dímero de esferas, dímero de elipsoides e trímeros de esferas.

Percebeu-se que dois fatores influenciam no perfil da distribuição de intensidades SERS: a concentração espacial do HS e a sua disponibilidade para a molécula. No caso dos dímeros o primeiro fator é o que determina o perfil da distribuição: no elipsoide, como o HS é mais concentrado, a distribuição apresenta um perfil exponencial com maior variabilidade de eventos que o observado para o dímero de esferas.

No trímero é o segundo fator que domina: temos dois HSs em uma única NP para a molécula acessar, como observado na figura 2 :

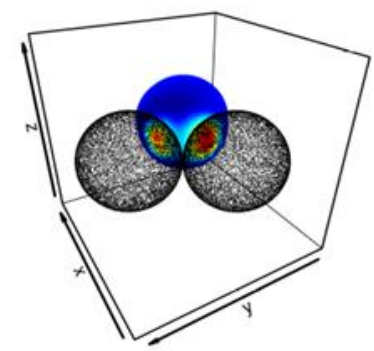

Figura 2. Hot spot de um trímero.

Isto leva a uma distribuição com menor variância, refletindo a maior probabilidade de observações de espectros SERS de maior intensidade.

\section{Conclusões}

Os resultados mostram que os histogramas de intensidades de um experimento SERS de uma única molécula carrega informações do HS e com isso obtémse as características das NPs presentes no substrato.

\section{Agradecimentos}

Os autores agradecem ao CNPq (PIBIC e 408985/20160) pelo apoio financeiro e ao Instituto de Química da UNICAMP pela infraestrutura.

1 Ru, E. C. L.; Etchegoin, P. G. Principles of Surface-Enhanced Raman Spectroscopy And Related Plasmonic Effects; Elsevier: Amsterdam, 2008.

${ }^{2}$ Le Ru, E. C.; Etchegoin, P. G.; Meyer, M. Journal of Chemical Physics 2006, 125. 